Portland State University

PDXScholar

Environmental Science and Management

Faculty Publications and Presentations

Environmental Science and Management

3-2016

\title{
Ecosystem Services in Managing Residential Landscapes: Priorities, Value Dimensions, and Cross-Regional Patterns
}

Kelli L. Larson

Arizona State University

Jennifer L. Morse

Portland State University, jlmorse@pdx.edu

Peter M. Groffman

Cary Institute of Ecosystem Studies

Neil D. Bettez

Cary Institute of Ecosystem Studies

Tara Trammell

University of Delaware

Follow this and additional works at: https://pdxscholar.library.pdx.edu/esm_fac

Part of the Ecology and Evolutionary Biology Commons, and the Sustainability Commons Let us know how access to this document benefits you.

\section{Citation Details}

Larson, K.L.; Nelson, K.C.; Samples, S.R.; Hall, S.J.; Bettez, N.; Cavender-Bares, J.; Groffman, P.M.; Grove, M.; Heffernan, J.B.; Hobbie, S.E.; Learned, J.; Morse, J.L.; Neill, C.; Ogden, L.A.; O'Neil-Dunne, J.; Pataki, D.E.; Polsky, C.; Chowdhury, R. Roy; Steele, M.; Trammell, T.L.E. 2015. Ecosystem services in managing residential landscapes: priorities, value dimensions, and cross-regional patterns. Urban Ecosystems.

This Article is brought to you for free and open access. It has been accepted for inclusion in Environmental Science and Management Faculty Publications and Presentations by an authorized administrator of PDXScholar. Please contact us if we can make this document more accessible: pdxscholar@pdx.edu. 


\title{
Ecosystem services in managing residential landscapes: priorities, value dimensions, and cross-regional patterns
}

\author{
K. L. Larson ${ }^{1}$ - K. C. Nelson ${ }^{2}$ - S. R. Samples ${ }^{3}$. \\ S. J. Hall ${ }^{4}$ - N. Bettez ${ }^{5}$. J. Cavender-Bares ${ }^{6,7}$. \\ P. M. Groffman ${ }^{5}$ - M. Grove ${ }^{6,7}$ • J. B. Heffernan ${ }^{8}$. \\ S. E. Hobbie ${ }^{6,7}$ • J. Learned ${ }^{4}$ - J. L. Morse ${ }^{9}$ C. Neill $^{10}$ • \\ L. A. Ogden ${ }^{11}$ - J. O'Neil-Dunne ${ }^{12}$ - D. E. Pataki ${ }^{13}$. \\ C. Polsky ${ }^{14} \cdot$ R. Roy Chowdhury ${ }^{15}$ - M. Steele ${ }^{16}$. \\ T. L. E. Trammell ${ }^{13}$
}

(C) Springer Science+Business Media New York 2015

\begin{abstract}
Although ecosystem services have been intensively examined in certain domains (e.g., forests and wetlands), little research has assessed ecosystem services for the most dominant landscape type in urban ecosystems - namely, residential yards. In this paper, we report findings of a cross-site survey of homeowners in six U.S. cities to 1) examine how residents subjectively value various ecosystem services, 2) explore distinctive dimensions of those values, and 3) test the urban homogenization hypothesis. This hypothesis posits that urbanization leads to similarities in the
\end{abstract}

\section{K. L. Larson}

kelli.larson@asu.edu

1 School of Geographical Sciences and Urban Planning, School of Sustainability, Arizona State University, Mail Code 5302, Tempe, AZ 85287-5302, USA

2 Department of Forest Resources and Department of Fisheries, Wildlife, and Conservation Biology, University of Minnesota, 115 Green Hall, 1530 Cleveland Ave. N, St. Paul, MN 55108, USA

3 Herberger Institute for Design and the Arts, Arizona State University, Tempe, AZ 85287, USA

4 School of Life Sciences, Arizona State University, 427 E Tyler Mall, Tempe, AZ 85287, USA

5 Cary Institute of Ecosystem Studies, Millbrook, NY 12545, USA

6 Department of Ecology, Evolution and Behavior, University of Minnesota, St. Paul, MN 55108, USA

7 Forest Service, Northern Research Station, Suite 350, 5523 Research Park Drive, Baltimore, MD 21228, USA

8 Nicholas School of the Environment, Duke University, Box 90328, Durham, NC 27708, USA

9 Department of Environmental Science and Management, Portland State University, PO Box 751, Portland, OR 97207, USA

10 The Ecosystems Center, Marine Biological Laboratory, 7 MBL St, Woods Hole, MA 02543, USA 
social-ecological dynamics across cities in diverse biomes. By extension, the thesis suggests that residents' ecosystem service priorities for residential landscapes will be similar regardless of whether residents live in the humid East or the arid West, or the warm South or the cold North. Results underscored that cultural services were of utmost importance, particularly anthropocentric values including aesthetics, low-maintenance, and personal enjoyment. Using factor analyses, distinctive dimensions of residents' values were found to partially align with the Millennium Ecosystem Assessment's categories (provisioning, regulating, supporting, and cultural). Finally, residents' ecosystem service priorities exhibited significant homogenization across regions. In particular, the traditional lawn aesthetic (neat, green, weed-free yards) was similarly important across residents of diverse U.S. cities. Only a few exceptions were found across different environmental and social contexts; for example, cooling effects were more important in the warm South, where residents also valued aesthetics more than those in the North, where low-maintenance yards were a greater priority.

Keywords Lawns $\cdot$ Residential landscapes $\cdot$ Land management $\cdot$ Human values $\cdot$ Ecosystem services $\cdot$ Urban sustainability

\section{Introduction}

The concept of ecosystem services is useful for interdisciplinary assessments of ecological functioning and their value to society (Vihervaara et al. 2010). In nearly a decade since the original Millennium Ecosystem Assessment (MEA; Millennium Ecosystem Board 2005), many studies have attempted to quantify, model, and estimate - in monetary terms - the value of ecosystem services, which can be simply defined as the benefits derived from ecosystems (Carpenter et al. 2009; Costanza et al. 2006; De Groot et al. 2006; Farber et al. 2002; Mahan et al. 2000; Nelson et al. 2009; Pataki et al. 2011). However, the cultural benefits of ecosystems - which the MEA specified as aesthetic, spiritual, recreational, and educational-remain woefully understudied (Chan et al. 2012). Furthermore, the ecosystem services framework has seldom been applied to social surveys that assess people's subjective values (Martín-López et al. 2012; Vihervaara et al. 2010),

To our knowledge, few studies have surveyed residents from distinct geographic areas to assess how they value different types of ecosystem services. A rare study by Martín-López et al. (2012) found that Spanish residents' perceptions of ecosystem services varied by the type

Department of Anthropology, Dartmouth University, HB 6047 Silsby Hall, Hanover, NH 03755, USA

12 Spatial Analysis Laboratory, Rubenstein School of Environment, \& Natural Resources, 205 George D. Aiken Center, Burlington, VT 05405-0088, USA

13 Department of Plant and Soil Sciences, University of Delaware, 531 S. College Ave, 152 Townsend Hall, Newark, DE 19716, USA

14 Florida Center for Environmental Studies, Florida Atlantic University, FL 3200 College Ave, Building DW Davie, Boca Raton, FL 33314, USA

15 Department of Geography, Indiana University, Student Building 120, 701 E. Kirkwood Ave, Bloomington, IN 47405, USA

16 Department of Crop and Soil Environmental Science, Virginia Tech, Smyth Hall, 185 Ag-Quad Ln \#330, Blacksburg, VA 24061, USA 
of ecosystem (e.g., coastal versus forested areas) and by lifestyle, socioeconomic status, and place of residence (i.e., urban versus rural). They found that rural people in Spain emphasized provisioning and regulating services such as food production and air purification) more so than urban residents, who tended to prioritize cultural services such as environmental education and aesthetics.

Research is needed to better understand human values and cultural aspects of ecosystem services and their management, especially in urban environments (Dahmus and Nelson 2014b; Kumar and Kumar 2008; Martín-López et al. 2012; Martini et al. 2015; Wallace 2007). While most ecosystem services research has focused on forests, wetlands, watersheds, and other natural systems (Chazdon 2008; Mahan et al. 2000; Vihervaara et al. 2010), far less research has focused on green infrastructure in cities, despite the considerable ecosystem services it provides (Pataki et al. 2011). Residential landscapes comprise a dominant type of green infrastructure in urban ecosystems (Cook et al. 2012). Inclusive of lawns (grass), patios (hard surfaces), or other elements, "residential landscapes" refer to the outdoor areas of people's homes, which are also referred to as "yards."

By focusing on residential landscapes, this research surveyed residents in diverse regions of the U.S. to advance knowledge about how residents value a wide range of ecosystem services provided by their own yards. Embodying social and environmental benefits, the ecosystem services provided by yards range from aesthetic appreciation and recreational enjoyment to water conservation and biodiversity protection, among others. Information on ecosystem services is useful to urban planners, landscape designers, and others who wish to enhance the benefits, or decrease the negative impacts, of residential yards. Understanding residents' subjective preferences is critical for ensuring the social desirability and sustainability of urban landscapes, while also overcoming situations certain in which societal benefits are not particularly valued by people.

Turfgrass - which is the most conventional land cover type in residential landscapes of the U.S. - is now so widespread that it rivals the numbers of acres dedicated to the most expansive irrigated crops grown in the U.S. (Milesi et al. 2005). The standard "industrial lawn" (Bormann et al. 2001) has been idealized as a monoculture of evenly green and weed-free grass that signifies-and is marketed as-pride, status, family, and citizenship (Robbins 2007; Steinberg 2006). If everyone actively subscribed to this American norm, one would expect similar ecosystem service preferences across the U.S., for instance, emphasizing green and weed-free yards. The idea of the monolithic lawn as well as homogeneous norms for neatness appears to suggest similarities in landscape preferences and practices. In other words, the uniformity of lawns and yard management across diverse ecosystems seems to support the homogenization hypothesis, which proposes that urbanization results in social and ecological outcomes that are more similar to each other than expected due to eco-climatic variation (Groffman et al. 2014).

We test the homogenization hypothesis by asking: how do residents' preferences for ecosystem services vary across six distinct urban ecosystems? This work is critical for revealing the extent to which urbanization leads to homogeneity in residential landscapes, which could in turn lead to widespread negative outcomes (e.g., excessive water consumption and chemical usage) due to the common practices (e.g., irrigation and fertilization) involved with intensively cultivating lawns (Bormann et al. 2001; Robbins 2007; Steinberg 2006). This analysis is timely given the rise of alternative landscapes that are replacing lawns in some places of the U.S. (e.g., drought-tolerant 'xeric' landscapes with gravel groundcover in arid Phoenix; Larson et al. 2009). 


\section{Background}

Recent biophysical research has begun to empirically test the urban homogenization thesis. One study demonstrated that residential landscapes across cities are becoming more similar in their ecological structure and functioning as compared to differences between native, undeveloped lands across regions (Groffman et al. 2014). Another study of soil moisture and surface water showed that, as urbanization occurs, humid cities get drier and arid cities get wetter, leading to a convergence in the distribution of water across urban regions (Steele et al. 2014).

Less urban ecosystems research has examined the social elements of homogenization. A recent study found that both irrigation and fertilization practices were different across urban regions as well as social groups (e.g., based on socioeconomic status and urban/suburban/ exurban location) (Polsky et al. 2014). Within cities such as Miami and Los Angeles, fertilization rates were higher among residences in suburban and rural areas as compared to urban ones. Yet across cities, the rates of fertilizer application were similar for these population density classes. This study also found that irrigation and fertilizer applications increased with income within and across cities (see Polsky et al. 2014 for more details).

Overall, Polsky et al. (2014) found that differentiation across cities was greater for irrigation than for fertilization. The authors concluded that: "these findings lend limited support to the popular, yet to-date untested, notion that urbanization is a homogenizing process, but strong evidence that homogenization is not as complete or pervasive as the conventional wisdom would suggest" (p. 4435). Since several recent studies have examined how landscape preferences and practices vary in relation to socioeconomic status, lifestyle characteristics, or other demographic factors (e.g., Grove et al. 2014; Larsen and Harlan 2006; Larson et al. 2009; Martín-López et al. 2012; Martini et al. 2015; Polsky et al. 2014), this paper focuses on geographic similarities and differences among broad regions of the U.S. Such comparative, cross-regional research is essential for examining the urban homogenization thesis, as well as being able to generalize human-environment interactions across distinctive geographies (Cook et al. 2012).

Several theoretical perspectives suggest different expectations for the macro-level drivers and outcomes associated with social homogenization, by which we mean similarities in people's preferences, behaviors, and so on. For example, although some globalization theorists suggest that capitalistic processes of hegemonic markets lead to the homogenization of cultures (Robins and Webster 1999), more nuanced arguments point to both the standardization and differentiation of society through consumer marketing (Kellner 2002). As Kellner (p. 292) explains:

"...it is important to present globalization as a strange amalgam of both homogenizing forces of sameness and uniformity and heterogeneity, difference, and hybridity, as well as a contradictory mixture of democratizing and antidemocratizing tendencies. On the one hand, globalization unfolds a process of standardization in which a globalized mass culture circulates the globe, creating sameness and homogeneity everywhere. On the other hand, globalized culture makes possible unique appropriations and developments everywhere, thus encouraging hybridity, difference, and heterogeneity to proliferate...."

The effects of globalization are similar to those involved with urbanization. Sameness may arise from professional standards in land use zoning, for example, or from the widespread development of planned subdivisions, which have been critiqued for their homogenous 
appearances (Jackson 1985). Cities have also been described as heterogeneous, particularly with respect to the close juxtaposition of spatially differentiated land uses within cities therein (Cadenasso et al. 2007; Grimm et al. 2000). The relative diversity of urban residents implies heterogeneity as well (Jackson 1985).

Social marketing research (Smith 1956) also stresses heterogeneity in societal preferences and decisions. The applied concept of market segmentation is grounded in the realization that producers must meet the heterogeneous needs of consumers (Wedel and Kamakura 2000). Market segmentation approaches are increasingly being used to foster behavior changes in the pursuit of sustainability (Grove et al. 2014; Troy 2008), in part because traditional educational approaches that rely on information dissemination have failed to spur environmental behaviors (Frisk and Larson 2011; McKenzie-Mohr and Smith 1999). McKenzie-Mohr and Smith's (1999) Community-Based Social Marketing (CBSM) technique requires situated understanding of the factors that motivate or constrain certain decisions or practices in specific contexts. Solutions are then tailored to those motivations and constraints for actions, which may vary across people or places. This market-based approaches to fostering sustainability necessitate place-based research on societal preferences, and by extension, marketing tools that can promote sustainable landscape alternatives in certain contexts.

Following from this review of pertinent literature, we expect some homogeneity and some heterogeneity in ecosystem service priorities across diverse cities of the U.S. First, we expected that the normative aesthetic characteristics of the industrial lawn (e.g., neat, green, weed-free) would be homogeneous across regions, suggesting a globalized concept of the residential yard in the U.S. Alternatively, the ecosystem services that we expected to differ are those closely coupled to local environmental and cultural conditions. Since ecosystem services can be heterogeneous as a result of biophysical conditions (De Groot et al. 2010), biophysical constraints are likely to influence priorities. For example, climatic conditions are likely to differentiate priorities across regions of the U.S., such that people in warm southerly climates will value cooling vegetation (e.g., microclimate regulation) more than people in cooler climates. Moreover, people in rainier cities of the eastern U.S. may be more concerned about flooding and runoff in their yards compared to residents in relatively arid cities of the West. In other words, we posit that urbanization causes residents' preferences for ecosystem services to be more similar across regions than expected based on underlying biophysical differences, except in cases where ecosystem services are driven by biophysical variation.

\section{Methods}

\section{Data collection}

During the summer of 2012, we conducted 134 in-person interviews with residential homeowners in six metropolitan areas of the U.S.: Minneapolis-St. Paul, Boston, Baltimore, Los Angeles, Miami, and Phoenix (Table 1). These cities represent diverse ecosystems in northern-to-southern and eastern-to-western parts of the U.S. The study sites were also selected based on the research team's ongoing work with the National Science Foundation's LongTerm Ecological Research (LTER) program. All but one site is part of the LTER network; Los Angeles was added to represent a western city.

The residents involved in these field surveys were selected based on their participation in telephone interviews, wherein we asked if we could contact the homeowner to conduct 
Table 1 Study Area Characteristics. Note the samples sizes were 94/40 for the East/West comparisons and 71/63 for the north/south comparisons, respectively

\begin{tabular}{llllll}
\hline Region & $\begin{array}{l}\text { Avg. Temp. } \\
{ }^{\circ} \mathrm{C}\left({ }^{\circ} \mathrm{F}\right)\end{array}$ & $\begin{array}{l}\text { Average precipitation } \\
\text { mm. (in.) }\end{array}$ & $\begin{array}{l}\text { North-South region } \\
\text { (temperature) }\end{array}$ & $\begin{array}{l}\text { East-West region } \\
\text { (moisture) }\end{array}$ & $\begin{array}{l}\text { Survey } \\
\text { sample (n) }\end{array}$ \\
\hline Minneapolis & $7.9(46.3)$ & $777.2(30.6)$ & $\mathrm{N} /$ cool & E/humid & 21 \\
Boston & $10.8(51.5)$ & $1,112.5(43.7)$ & $\mathrm{N} /$ cool & E/humid & 31 \\
Baltimore & $16.3(61.4)$ & $1,077.0(42.4)$ & $\mathrm{N} /$ cool & E/humid & 19 \\
Los Angeles & $18.5(65.4)$ & $378.5(14.9)$ & $\mathrm{S} /$ warm & W/arid & 10 \\
Phoenix & $23.9(75.1)$ & $208.3(8.2)$ & $\mathrm{S} /$ warm & W/arid & 30 \\
Miami & $24.9(76.8)$ & $1,272.5(50.1)$ & $\mathrm{S} /$ warm & E/humid & 23 \\
\hline
\end{tabular}

interviews/surveys and ecological fieldwork in the future. For the telephone survey, we randomly selected households that were stratified to reach a diversity of residential neighborhoods based on urban density (high, medium, low), socioeconomic status (high, medium, low), and life stage (younger years, family life, mature years) from Claritas PRIZM classes (see Polsky et al. 2014 for more details and findings from the telephone survey). ${ }^{1}$

The stratification scheme for the preliminary telephone survey allowed for sampling similar types of neighborhoods across cities. Of the 9,480 survey respondents, 5,797 (61\%) agreed to be contacted for follow-up fieldwork. To recruit participants for the present study, the agreeable households were first sent information letters and were later contacted by phone. Up to three attempts were made during diverse periods of the day until we obtained a sample of 20-30 households from each city (see Table 1). ${ }^{2}$ This field-based sample of residents comprised the survey data analyzed in this paper.

With each household we conducted a written survey with closed-ended questions from which ordinal data on ecosystem service preferences were collected. Interviews were also conducted, and ecological data were collected, but the analysis presented herein focuses on select survey variables. The survey consisted of nine closed-ended questions, two of which were analyzed for this paper: 1) "What criteria guide your household's vegetation (grass, trees, and other plants) choices?" and 2) "What criteria guide your yard management choices overall?" Survey responses were gauged on a 4-point ordinal scale ranging from $0=$ not important to $1=$ low, 2-medium, and 3 =high importance (see Table 2), in order to gauge the value that residents place on particular ecosystem services.

For each of the two questions, residents rated multiple ecosystem services, which were worded in lay terms (Tables 3 and 4). For example, biodiversity was written as "the [yard] offers a variety of plants," and aesthetics was written as "the [vegetation] creates a beautiful yard." The list of ecosystem services evaluated was based on the MEA categories (provisioning, regulating, supporting, and cultural; Millennium Ecosystem Board 2005) as well as previous research specific to landscape management (Dahmus and Nelson 2014b; Larsen and Harlan 2006; Larson et al. 2009; Martin et al. 2003; Martini et al. 2015). Based on this information, we had repeated discussions about the most significant ecosystem services and how to word them until the research team was satisfied with a comprehensive list of items.

\footnotetext{
${ }^{1}$ See also the Claritas web site at http://www.claritas.com/.

${ }^{2}$ All cities had at least 20 research participants, yet some data from Los Angeles was eliminated from the analysis due to errors. This explains the relatively low sample size for LA.
} 
Table 2 Descriptive statistics for ecosystem services

\begin{tabular}{|c|c|c|c|c|}
\hline Ecosystem services & MEA type & Median & Mean & Std. Dev. \\
\hline Aesthetics $($ rho $=0.65)$ & Cultural/Aest. & 3.0 & 2.45 & 0.76 \\
\hline [Plants] create a beautiful yard & Cultural/Aest. & $\overline{3.0}$ & 2.54 & 0.74 \\
\hline Creates a beautiful [yard] & Cultural/Aest. & 3.0 & 2.36 & 0.93 \\
\hline [Yard] provides personal enjoyment & Cultural/Rec. & 3.0 & 2.25 & 1.07 \\
\hline Low maintenance $($ rho $=0.48)$ & Cultural/Rec. & $\underline{2.5}$ & 2.31 & $\underline{0.80}$ \\
\hline [Plants] are easy to maintain & Cultural/Rec. & 3.0 & 2.46 & 0.79 \\
\hline [Yard] is easy to maintain & Cultural/Rec. & 3.0 & 2.16 & 1.07 \\
\hline [Yard] reduces weeds & Cultural/Aest. & 3.0 & 2.15 & 1.08 \\
\hline [Plants are] suited to my yard conditions & Supporting & 2.0 & 2.01 & 1.16 \\
\hline [Yard] makes things green & Cultural & 2.0 & 1.93 & 1.17 \\
\hline [Plants] provide shades \& cooling ${ }^{\wedge}$ & Regulating & 2.0 & 1.91 & 1.15 \\
\hline Floral biodiversity $(\mathrm{rho}=\mathbf{0 . 5 3})$ & Provisioning & $\underline{2.0}$ & $\underline{1.82}$ & $\underline{1.01}$ \\
\hline [Yard] offers flowers & Provisioning & $\overline{2.0}$ & $\overline{1.96}$ & $\overline{1.09}$ \\
\hline [Yard] offers a variety of plants & Provisioning & 2.0 & 1.69 & 1.22 \\
\hline Neat aesthetic $($ rho $=0.68)$ & Cultural/Aest. & 2.0 & $\underline{1.76}$ & $\underline{1.10}$ \\
\hline [Plants] are neat \& orderly & Cultural/Aest. & $\overline{2.0}$ & $\overline{1.91}$ & $\overline{1.15}$ \\
\hline [Yard] is neat \& orderly & Cultural/Aest. & 2.0 & 1.61 & 1.25 \\
\hline [Yard] looks natural & Cultural/Aest. & 2.0 & 1.70 & 1.27 \\
\hline [Plants] provide privacy \& seclusion & Cultural/Rec. & 2.0 & 1.54 & 1.19 \\
\hline [Yard] improves the air we breathe & Regulating/Cultural $^{\wedge}$ & 2.0 & 1.34 & 1.25 \\
\hline Nature provisioning $($ rho $=0.48)$ & Provisioning & $\underline{1.5}$ & $\underline{1.40}$ & $\underline{1.03}$ \\
\hline [Plants] support wildlife & Provisioning & $\overline{2.0}$ & $\overline{1.54}$ & $\overline{1.21}$ \\
\hline [Plants] are native to the area & Provisioning & 1.5 & 1.27 & 1.19 \\
\hline Low cost $($ rho $=0.76)$ & Cultural/Econ. & $\underline{1.5}$ & $\underline{1.31}$ & $\underline{1.10}$ \\
\hline [Plants] are inexpensive & Cultural/Econ. & $\overline{2.0}$ & $\overline{1.40}$ & $\overline{1.16}$ \\
\hline [Yard] is low cost & Cultural/Econ. & 1.0 & 1.23 & 1.18 \\
\hline [Plants] provide food & Provisioning & 1.0 & 1.33 & 1.20 \\
\hline Environmental services $($ alpha $=0.75)$ & Mixed & $\underline{1.0}$ & $\underline{1.25}$ & $\underline{1.07}$ \\
\hline [Yard] provides nutrients to improve soil & Supporting & $\overline{2.0}$ & $\overline{1.40}$ & $\overline{1.32}$ \\
\hline [Yard] reduces flooding/standing water & Regulating & 1.0 & 1.28 & 1.31 \\
\hline [Yard] reduces pollution in local water bodies & Regulating & 0.0 & 1.07 & 1.30 \\
\hline [Yard] supports socializing & Cultural/Rec. & 1.0 & 1.08 & 1.14 \\
\hline [Yard] helps with climate change & Regulating & 0.0 & 0.96 & 1.21 \\
\hline Local cultural values $($ alpha $=0.75)$ & Cultural & $\underline{0.3}$ & $\underline{0.70}$ & $\underline{0.84}$ \\
\hline [Yard] provides nature learning/exploring** & Cultural/Educ. & $\overline{0.0}$ & $\overline{1.02}$ & 1.22 \\
\hline [Yard] reflects my tradition \& heritage & Cultural/Norm & 0.0 & 0.66 & 1.03 \\
\hline [Yard] reflects my religious/spiritual values & Cultural/Sprit. & 0.0 & 0.42 & 0.81 \\
\hline [Plants are] common in my neighborhood & Cultural/Norm & 0.0 & 0.61 & 0.87 \\
\hline [Plants] were planted by previous owner & Cultural/Norm & 0.0 & 0.57 & 0.86 \\
\hline [Yard] is common in my neighborhood & Cultural/Norm & 0.0 & 0.49 & 0.79 \\
\hline
\end{tabular}

Valid $N=134$. Raw individual variables are italicized, and composite scales are in bold, with underlined statics followed by the variables included in that index. The range for all variables was $0-3$, where $0=$ not important and 1,2 , and 3 reflected low, medium, and high importance, respectively

*Verbatim wording for this variable was: provides shade and helps cool the climate, **Verbatim wording for this variable was: provides opportunities to explore and learn about nature and the environment

${ }^{\wedge}$ This variable represents regulation of air quality but could also be seen as a cultural/health benefit 


\section{Data analysis}

The survey data were entered into an SPSS database for statistical analyses. First, we conducted descriptive statistics on the ecosystem preferences variables from the two survey questions. These two sets of variables differentiated between vegetation choices specifically (12 services evaluated) and residential land management generally (20 services) (Table 2). These data allowed aggregated consideration of low to high priorities in terms of the benefits of residential landscapes that people value most when making decisions about their yards.

Second, we used factor analysis to examine dimensions of ecosystem service values and to reduce the variables into a smaller subset of composite variables for the subsequent analysis of geographic differences. Principal components extraction with a promax rotation was performed for three sets of ecosystem service variables. First, we analyzed the relevant services provided by vegetation choices (12) and yard management (20). Then, both sets of variables were combined (32) to evaluate landscaping priorities as a whole. As is standard practice, eigenvalues $>1$ indicated significant dimensions worthy of consideration and interpretation (Kim and Mueller 1978). Loadings of 0.5 or higher were included for each factor. However, in cases where a variable did not load highly $(>0.5)$ on any of the factors, the variable and its loading value were included with the factor on which it loaded most highly. As seen in Tables 3, 4 and 5, all loadings presented were higher than 0.35 .

Several of the final ecosystem service variables for the cross-regional comparisons were composite indices based on the average of two or three variables. For those indices with two

Table 3 Factor analysis results: variable loadings for vegetation choices

\begin{tabular}{|c|c|c|c|c|c|}
\hline $\begin{array}{l}\text { Ecosystem service } \\
\text { value variables }\end{array}$ & $\begin{array}{l}\text { Local nature } \\
1\end{array}$ & $\begin{array}{l}\text { Local conditions } \\
2\end{array}$ & $\begin{array}{l}\text { Neat aesthetics } \\
3\end{array}$ & $\begin{array}{l}\text { Low cost } \\
4\end{array}$ & $\begin{array}{l}\text { Easy maintenance } \\
5\end{array}$ \\
\hline Native plants $(\mathrm{P})$ & 0.812 & & & & \\
\hline Wildlife (P) & 0.768 & & & & \\
\hline Food $(\mathrm{P})$ & 0.659 & & & & \\
\hline Cooling (R) & 0.479 & & & & \\
\hline Past decisions (C) & & 0.762 & & & \\
\hline Local conditions (S) & & 0.644 & & & \\
\hline Common Locally (C) & & 0.547 & & & \\
\hline Beauty (C) & & & 0.775 & & \\
\hline Neat (C) & & & 0.756 & & \\
\hline Privacy $(\mathrm{C})$ & & & 0.470 & & \\
\hline Inexpensive $(\mathrm{C})$ & & & & 0.906 & \\
\hline Easy to maintain $(\mathrm{C})$ & & & & & 0.942 \\
\hline Eigenvalues & 2.792 & 1.550 & 1.339 & 1.050 & 1.031 \\
\hline$\%$ Variance (Cumulative) & $\begin{array}{l}23.3 \% \\
(23.3 \%)\end{array}$ & $\begin{array}{l}12.9 \% \\
(36.2 \%)\end{array}$ & $\begin{array}{l}11.2 \% \\
(47.3 \%)\end{array}$ & $\begin{array}{l}8.7 \% \\
(56.1 \%)\end{array}$ & $\begin{array}{l}8.6 \% \\
(64.7 \%)\end{array}$ \\
\hline Cronbach's Alpha & 0.66 & 0.57 & 0.46 & n.a. & n.a. \\
\hline
\end{tabular}

Notes: analysis used principal components extraction with promax rotation. Highest loading value for each variable is presented. The parenthetic references for the ES variables are: $C$ cultural, $P$ provisioning, $R$ regulating, and $S$ supporting 
Table 4 Factor analysis results: variable loadings for yard choices. Note: analysis used principal components extraction with promax rotation

\begin{tabular}{|c|c|c|c|c|c|}
\hline \multirow[t]{2}{*}{$\begin{array}{l}\text { Ecosystem service } \\
\text { value variables }\end{array}$} & $\begin{array}{l}\text { Local } \\
\text { values }\end{array}$ & $\begin{array}{l}\text { Environmental } \\
\text { maintenance }\end{array}$ & $\begin{array}{l}\text { Floral } \\
\text { biodiversity }\end{array}$ & $\begin{array}{l}\text { Neat } \\
\text { aesthetics }\end{array}$ & $\begin{array}{l}\text { Low } \\
\text { cost }\end{array}$ \\
\hline & 1 & 2 & 3 & 4 & 5 \\
\hline Spiritual values (C) & 0.793 & & & & \\
\hline Looks natural (C) & 0.777 & & & & \\
\hline Learning $(\mathrm{C})$ & 0.764 & & & & \\
\hline Tradition $(\mathrm{C})$ & 0.705 & & & & \\
\hline Socializing (C) & 0.599 & & & & \\
\hline Climate (R) & 0.463 & & & & \\
\hline Air quality (M) & 0.389 & & & & \\
\hline Easy $(\mathrm{C})$ & & 0.816 & & & \\
\hline Water quality (R) & & 0.586 & & & \\
\hline Drainage $(\mathrm{R})$ & & 0.571 & & & \\
\hline Weed-free $(\mathrm{C})$ & & 0.521 & & & \\
\hline Soil nutrients (S) & & 0.486 & & & \\
\hline Flowers (P) & & & 0.936 & & \\
\hline Plant variety $(\mathrm{P})$ & & & 0.842 & & \\
\hline Greenery (C) & & & 0.483 & & \\
\hline Beauty (C) & & & & 0.892 & \\
\hline Enjoyment (C) & & & & 0.549 & \\
\hline Neat (C) & & & & 0.540 & \\
\hline Low cost $(\mathrm{C})$ & & & & & 0.825 \\
\hline Common (C) & & & & & 0.570 \\
\hline Eigenvalues & 5.884 & 2.142 & 1.586 & 1.196 & 1.013 \\
\hline$\%$ Variance (Cumulative) & $\begin{array}{l}29.4 \% \\
(29.4 \%)\end{array}$ & $\begin{array}{l}10.7 \% \\
(40.1 \%)\end{array}$ & $\begin{array}{l}7.9 \% \\
(48.1 \%)\end{array}$ & $\begin{array}{l}6.0 \% \\
(54.0 \%)\end{array}$ & $\begin{array}{l}5.1 \% \\
(59.1 \%)\end{array}$ \\
\hline Cronbach's Alpha & 0.81 & 0.70 & 0.67 & 0.57 & $\mathrm{rho}=0.38$ \\
\hline
\end{tabular}

Notes: analysis used principal components extraction with promax rotation. Highest loading value for each variable is presented. The parenthetic references for the ES variables are: $C$ cultural, $P$ provisioning, $R$ regulating, and $S$ supporting

variables only, Spearman's rho tests identified bivariate correlations. For composite indices with three variables, Cronbach's alpha tests denote internal consistency. The common criterion of an alpha value $>0.7$ indicates reliable indices. The 32 individual variables were ultimately reduced down to 22 variables (Table 2). The overall goal in developing the composite indices was to create parsimonious ecosystem service variables for the third analysis, considering both their statistical reliability-as measured by Spearman's rho and Cronbach's alpha, and face validity - as interpreted by a collaborative group of researchers.

Third, we used non-parametric statistics to test the homogeneity among our six cities, comparing the humid East and arid West, and the cold North and warm South (Table 1). Mann-Whitney U tests were used to test for statically significant differences between the East and West as well as the North and South $(p<0.05)$. 
Table 5 Factor analysis results: variable loadings for both vegetation and yard choices notes: analysis used principal components extraction with promax rotation

\begin{tabular}{llllllllllll}
\hline $\begin{array}{l}\text { Ecosystem } \\
\text { service value } \\
\text { variables }\end{array}$ & 1 & 2 & 3 & 4 & 5 & 6 & 7 & 8 & 9 \\
\hline
\end{tabular}

\begin{tabular}{|c|c|c|c|c|c|c|c|c|c|}
\hline Spiritual values (C) & 0.856 & & & & & & & & \\
\hline Soil nutrients (S) & 0.774 & & & & & & & & \\
\hline Water quality (R) & 0.760 & & & & & & & & \\
\hline Climate change (R) & 0.751 & & & & & & & & \\
\hline Tradition $(\mathrm{C})$ & 0.729 & & & & & & & & \\
\hline Learning $(\mathrm{C})$ & 0.630 & & & & & & & & \\
\hline Drainage $(\mathrm{R})$ & 0.530 & & & & & & & & \\
\hline Air quality (R) & 0.482 & & & & & & & & \\
\hline Beautiful yard (C) & & 0.917 & & & & & & & \\
\hline Beautiful plants (C) & & 0.834 & & & & & & & \\
\hline Neat plants $(C)$ & & 0.392 & & & & & & & \\
\hline Neat yard $(C)$ & & 0.430 & & & & & & & \\
\hline Weed-free $(\mathrm{C})$ & & 0.390 & & & & & & & \\
\hline $\begin{array}{l}\text { Inexpensive } \\
\text { plants (C) }\end{array}$ & & & 0.955 & & & & & & \\
\hline Low cost yard (C) & & & 0.897 & & & & & & \\
\hline Common yard (C) & & & 0.367 & & & & & & \\
\hline Local conditions (S) & & & & 0.801 & & & & & \\
\hline Cooling (R) & & & & 0.655 & & & & & \\
\hline Socializing $(\mathrm{C})$ & & & & 0.582 & & & & & \\
\hline Looks natural (C) & & & & 0.541 & & & & & \\
\hline Wildlife (P) & & & & & 0.789 & & & & \\
\hline Native plants $(\mathrm{P})$ & & & & & 0.673 & & & & \\
\hline Food $(\mathrm{P})$ & & & & & 0.555 & & & & \\
\hline Greenery (C) & & & & & -0.515 & & & & \\
\hline Flowers $(\mathrm{P})$ & & & & & & 0.860 & & & \\
\hline Plant variety $(\mathrm{P})$ & & & & & & 0.770 & & & \\
\hline Plants easy $(\mathrm{C})$ & & & & & & & 0.890 & & \\
\hline Yard easy (C) & & & & & & & 0.794 & & \\
\hline Past decision $(\mathrm{C})$ & & & & & & & & 0.837 & \\
\hline Common plants $(\mathrm{C})$ & & & & & & & & 0.418 & \\
\hline Privacy $(\mathrm{C})$ & & & & & & & & & 0.790 \\
\hline Enjoyment (C) & & & & & & & & & -0.599 \\
\hline Eigenvalues & 7.442 & 3.237 & 2.370 & 1.718 & 1.494 & 1.358 & 1.131 & 1.085 & 1.021 \\
\hline \multirow{2}{*}{$\begin{array}{l}\text { \% Variance } \\
\quad \text { (Cumulative) }\end{array}$} & $23.3 \%$ & $10.1 \%$ & $7.4 \%$ & $5.4 \%$ & $4.7 \%$ & $4.2 \%$ & $3.5 \%$ & $3.4 \%$ & $3.2 \%$ \\
\hline & $(23.3 \%)$ & $(33.4 \%)$ & $(40.9 \%)$ & $(46.2 \%)$ & $(50.8)$ & $(55.0 \%)$ & $(58.6 \%)$ & $(62.0 \%)$ & $(65.2 \%)$ \\
\hline Cronbach's Alpha & 0.86 & 0.76 & 0.75 & 0.61 & 0.66 & $\mathrm{rho}=0.54$ & $\mathrm{rho}=0.47$ & $\mathrm{rho}=0.39$ & \\
\hline
\end{tabular}

Notes: Analysis used principal components extraction with promax rotation. Factor labels are: 1) CulturalEnvironmental Values, 2) Aesthetics, 3) Low Costs, 4) Local Conditions, 5) Local Wildlife, 6) Floral Biodiversity, 7) Easy Maintenance, 8) Local Legacies, and 9) Privacy. Loadings in parentheses are only presented to address the implications for tradeoffs between ecological services and cultural desires for neatness for the fifth factors

Notes: analysis used principal components extraction with promax rotation. Highest loading value for each variable is presented. The parenthetic references for the ES variables are: $C$ cultural, $P$ provisioning, $R$ regulating, and $S$ supporting 


\section{Findings}

\section{Ecosystem service values for land management}

For both vegetation choices in particular and yard management in general, beauty (aesthetics) and ease-of-maintenance were rated by residents as the most important priorities for their outdoor landscapes (Table 2). These variables also exhibited relatively low variation; for example, $65 \%$ of the sample rated aesthetics as very important and an additional $28 \%$ said aesthetics were moderately important. A weedfree aesthetic was also highly valued, along with personal enjoyment. Although aesthetic value was a central priority in terms of beauty and weed-free yards, other aesthetic characteristics (e.g., greenness and a natural look) were rated moderately important. Bimodal distributions indicated a division in the sample into those who rated a green appearance, a natural-looking yard, and neatness as moderately-to-very important versus those who rate them as not important at all, with very few stating that these were of low importance.

Moderately important benefits of vegetation included plants suited to local yard conditions, plants that are neat and orderly, and those that provide cooling benefits. These were followed in importance by plants that offer privacy, attract wildlife, and are inexpensive. Of relatively low value, in aggregate, were plants that are native to the local ecosystems and those that provide food. Lastly, maintaining vegetation that is common to people's neighborhoods and keeping plants that were planted by another person were of little importance to the sample as a whole.

A green aesthetic and the provisioning of flowers were quite important for land management choices, followed by a natural-looking yard and a variety of plants (biodiversity). Orderliness was also moderately valued, in addition to supporting services associated with soil nutrients and air quality. The following were expressed as low importance priorities: regulating water drainage and reducing pollution, plus minimizing yard expenses and using yards to socialize. Of least value to residents were climate change regulation and several cultural services (i.e., learning, tradition, spiritual values, and commonality in the neighborhood).

\section{Dimensions and scales for ecosystem services}

In the principal components analysis, the individual variables clustered along several significant dimensions. The interpretation of factors, or components, for ecosystem service values emphasized the highest loading variables $(>0.6$, as shown in bold in Tables 3,4 and 5). The labels assigned to each factor (in italics throughout this section) reflect their overarching meaning, as determined by the collaborative research team.

The first factor analysis - focusing on the values placed on vegetation choices specifically-produced five factors that account for $65 \%$ of the variance in the data (Table 3 ). The first factor reflected values placed on local nature, particularly in terms of the provisioning of native plants and wildlife habitat as well as food. The second factor, local conditions, included high loadings for plants planted by other people in the past and those suitable to yard conditions. The third factor represented a neat aesthetic. The fourth was labeled low cost, since this single variable was the only one that loaded on this factor. Fifth, easy maintenance was another single-variable factor. 
The second factor analysis examined the dimensions of values for yard management in general, producing five factors that explained $59 \%$ of the variance (Table 4 ). The first factor stressed culturally-based environmental values including yards that embody spiritual values, look natural, provide opportunities to learn about nature, and reflect personal heritage or tradition, among a few other factors with relatively low loadings. Next, an environmental maintenance factor emerged with a distinctively high loading for the low-maintenance variable and lower loadings for regulating and supporting services such as reducing pollution, draining water, and improving soil nutrients. The third factor signified floral biodiversity, with the provisioning of flowers and a variety of plants loading most strongly on this dimension. Similar to the first analysis of vegetation choices, the fourth factor stressed a neat aesthetic, with a particularly high loading for the importance of having a beautiful landscape. Similarly, the fifth factor emphasized low-cost yards.

Lastly, the factor analysis of all variables together, combining vegetation choices and yard management in general, replicated many of the factors distinguished in the first two factor analyses. With $65 \%$ of the variability in the data accounted for by nine factors, the first factor reflected cultural-environmental values, with a mix of supporting environmental services, plus climate change regulation, and cultural services that emphasized spiritual values, learning opportunities, and local heritage. This factor had high loadings for ecosystem services that were of relatively low value to the residents sampled (Table 5).

The second factor, aesthetics, had the highest loadings for the beauty of both vegetation and yards overall. The two neatness variables and the weed-free variable also loaded on this factor, although the loadings were $<0.5$. Third, the two variables for inexpensive plants and yards reflect a low cost factor. Fourth, a local conditions factor included the value placed on having suitable local conditions for plant choices, in addition to the benefits associated with cooling, socializing, and having a natural-looking yard.

The fifth factor stressed local wildlife inclusive of wildlife and native plants. This factor also had negative loadings, albeit low ones, for greenery as well as neat plants and yards. Interestingly, the opposition between these aesthetic characteristics and local nature suggested a tradeoff between ecological benefits and the neat, green aesthetic of the traditional lawn.

Also similar to the analysis of yard choices, the sixth factor represented the provisioning of floral biodiversity based upon loadings for variety of plants and flowers. The seventh represents the two easy maintenance variables. The eighth and ninth factors had high loadings that reflected the local legacies of past decisions and privacy.

Based on the factor analysis, as well as conceptual considerations, eight parsimonious composite indices were created by averaging two or three individual variables (see Table 2). Although the development of the composite indices representing reliable ecosystem service values was informed by the factor analysis, the variables for the subsequent analyses were simplified because (1) some dimensions had variables with wide-ranging and relatively weak loadings; (2) many did not meet the alpha $>0.70$ criterion; and, (3) others were weak in terms of face validity or otherwise difficult to interpret (such as the first factor in the third analysis of all variables; see Table 5).

With a total of twenty-two final variables, fourteen remained single-item survey responses (Table 2). The two composite variables with three contributing variables (i.e., supporting environmental services and local cultural values) both had alpha values $>0.70$, whereas the six two-variable indices all had Spearman rho values of 0.5 or higher (see Table 2). 


\section{Homogeneity and heterogeneity in ecosystem service preferences}

Ecosystem service values for residential landscapes exhibited substantial homogeneity across the eastern and western as well as northern and southern study sites we sampled. Of the MannWhitney $U$ tests on the 22 ecosystem services examined, about three-fourths (16) of the value variables were not statistically different among regions, indicating similar priorities across regions. Landscape values associated with the aesthetic characteristics of the traditional lawn ideal (e.g., green, weed-free, and neat) were among the homogeneous priorities across regions of the U.S. Several other cultural values were similar in their importance across regions, such as local values, tradition, and costs. Biodiversity and supporting environmental services, inclusive of soil nutrients and controlling or treating water, were also similarly valuedalthough not highly_ across diverse contexts.

Only six values for residential landscapes exhibited heterogeneity across the climatic regions. Between the southern and northern cities, residents differed in terms of the value they place on aesthetic versus low-maintenance yards (Fig. 1). While people in the warm Sunbelt valued beautiful landscapes more than low-maintenance landscapes (Mann-Whitney $p$ value $=0.036$ ), those in the North emphasized the practicality of low-maintenance yards over their aesthetic appearance $(p=0.020)$. The third ecosystem service value that differed across the North and South was the cooling ability of vegetation, which was a higher priority in warmer cities than cooler ones $(p=0.047)$.

Residents in the East placed higher importance on low-cost yards than those in the western U.S. (Mann-Whitney $p$ value $=0.045$ ), perhaps due to higher income levels among residents sampled in the West (Pearson chi-square $=3.76, p=0.041$ ). Additionally, eastern residents placed a higher value on local nature (biota) provisioning compared to those in the West $(p=0.009)$. Residents in the East also placed more importance on climate change regulation compared to those in the West $(p=0.013)$ Fig. 2.

\section{Discussion}

\section{Geographic homogeneity and heterogeneity in ecosystem service priorities}

Residents' preferences for the ecosystem services provided by their yards were largely similar across the regions sampled in this study, thereby supporting the urban homogenization thesis.
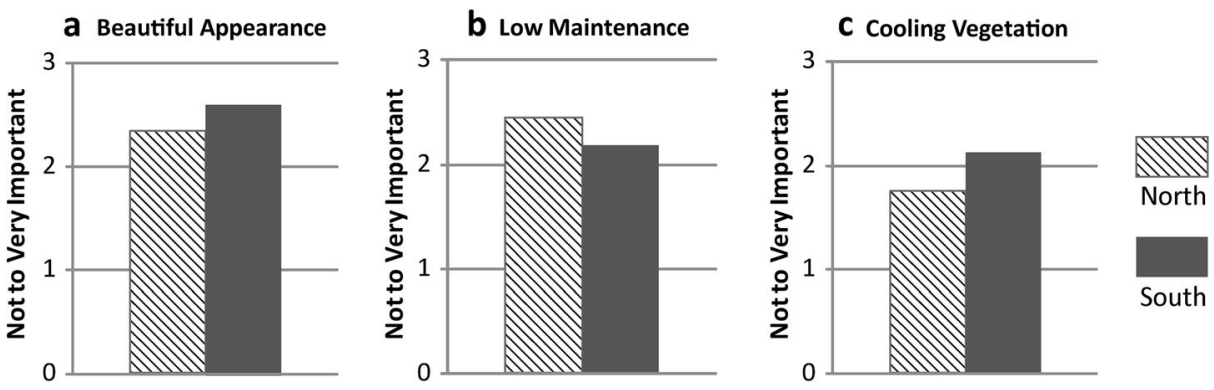

Fig. 1 Value differences for ecosystem services of residential yards: the cool North versus the warm South based on Mann-Whitney $U$ test $p$ values $<0.05$ 


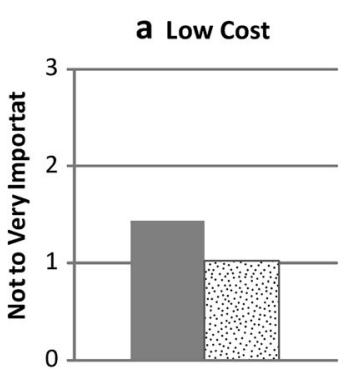

b Local Nature Provisioning

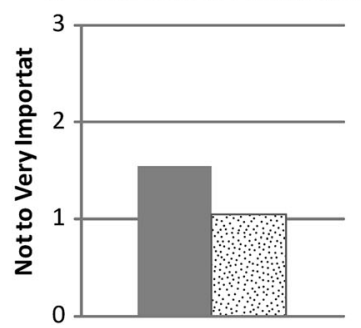

C Climate Change Regulation

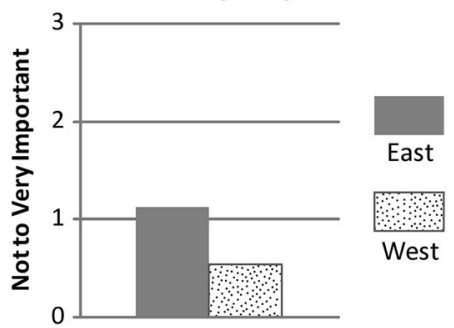

Fig. 2 Value differences for ecosystem services of residential yards: the humid East versus the arid West based on Mann-Whitney $U$ test $p$ values $<0.05$

As expected, the traditional lawn aesthetic was similarly important across the U.S., with weedfree yards being of utmost importance to residents. The factors driving this homogenization are unclear and likely complex (Kellner 2002). The homogenizing forces of consumer marketing may contribute to this finding given the advertising campaigns that promote the industrial lawn by the yard-care industry (Robbins 2007; Robbins and Sharp 2003). Indeed, social norms further reinforce expectations for neat landscapes, which accompany notions of the idealized lawn (Larson and Brumand 2014; Nassauer 1988). While these values and norms may be pervasive in western countries, we cannot claim that this trend applies to all places. Since small sample sizes in select regions of the U.S. limit the generalizability of our findings, further research should test these claims.

It is important to acknowledge that although aesthetics and other ecosystem services were similarly valued across residents in the study regions, this does not necessarily mean that individuals hold the same notion of what constitutes beauty. This was evident in the bimodal distributions of certain variables, which reflect trends reported in other studies. For example, the bimodal distributions for natural-looking yards and native vegetation indicated that such 'naturalistic' landscapes are valued by some people, but not others. Historically, such naturalistic landscapes have been negatively viewed as messy and unsafe (Nassauer 1995). Yet this trend may be shifting, and the desire for more 'natural' landscapes may be on the rise. Beyond the present study, this can be seen in the movement away from the homogeneous lawn (Robbins 2007) and toward alternative landscapes such as drought-tolerant, desert-like 'xeric' yards in arid Phoenix, Arizona (Larson et al. 2009) or low-input landscapes with native species in Minneapolis-St. Paul, Minnesota (Dahmus and Nelson 2014a). Longitudinal research would be useful in tracking such shifts in landscaping preferences, practices, and norms over time.

Consistent with our expectations and previous research (Kellner 2002; Polsky et al. 2014), ecosystem service preferences were not entirely homogenous across metropolitan regions of the U.S. Heterogeneity was identified in residents' landscaping priorities for some ecosystem services. In particular, people in warmer, southerly cities value cooling vegetation more so than those in cooler, northerly regions. Yet the relative humidity of regions did not matter for water drainage, which was similarly important across the humid East and the arid West. Additional research should examine ecosystem service priorities across different biophysical settings, since landscape preferences and designs may vary based on environmental conditions and goals. This is particularly the case since the sustainability implications of yard management may necessitate differentiated approaches to landscape design and maintenance (Polsky et al. 2014). 
Other regional differences in ecosystem service priorities indicate varying values placed on aesthetics, maintenance, and the cost of yards across the regions we studied, perhaps due to different lifestyles or norms. For example, people in northern and eastern cities may be pragmatically focused respectively on low-maintenance and low-cost landscapes; in comparison, people in southerly, Sunbelt cities tended to place higher priority on appearances. Residents of cities in the eastern U.S. also exhibited relatively strong environmental values, in that they placed higher priority on local nature provisioning and climate change regulation compared to those in western cities. Future studies should delve deeper into these findings in order to reveal how and why the norms and priorities vary across places as well as people.

\section{Distinctive dimensions of ecosystem services}

This research provides empirical evidence that subjective judgments align along the Millennium Ecosystem Assessment (Millennium Assessment Board 2005) classifications, at least partially. In particular, residents' expressed values stressed the importance of two types of provisioning services: floral biodiversity (flowers and plant diversity) and local nature (native plants and wildlife). With regard to regulating and supporting services, the value dimensions that emerged from the factor analysis tended to group these types of ecosystem services together (e.g., in the environmental services factor stressing water drainage, pollution reduction, and soil nutrients; Table 2). Yet people's values for these services were also linked to lowmaintenance yard priorities (see environmental maintenance factor in Table 4) as well as local cultural values (see cultural-environmental values in Table 5). Overall, these groupings suggest that regulating and supporting services tend to be valued in conjunction with cultural values that reflect personal and societal priorities. These results underscore that landscapes designed to achieve environmental goals (e.g., biodiversity conservation, water regulation) must also be designed to address people's preferences for low-maintenance, aesthetically appealing yards, which may vary by personal tastes and lifestyles (Larson et al. 2009).

The majority of dimensions that emerged from our factor analysis stressed cultural services, which appear more plentiful than previous ecosystem services initiatives (e.g., the MEA) indicate. While cultural services include aesthetics, recreation, education, and spirituality, as stressed by the Millennial Ecosystem Assessment, these general cultural services are more nuanced and could be further divided into specific attributes based on specific contexts. Applied to residential landscapes, for example, aesthetic preferences could be differentiated by a manicured aesthetic (e.g., the hyper-green, weed-free lawn aesthetic) versus more naturalistic ones (e.g., native plants with less pruning). Recreation can also mean different things to different people, ranging from passive 'leisure time' that is relatively relaxing to active 'play time' that is more physically demanding.

Additional research is needed to fully theorize and detail cultural services in relation to complex constructs such as 'sense of place' (Davenport and Anderson 2005; Williams and Stewart 1998) and social norms (Schultz et al. 2007; Larson and Brumand 2014). Regarding norms, residents did not stress those variables as important for their yard management choices, perhaps due to how they were operationalized in this study (e.g., plants or yards area common to my neighborhood) (see bottom of Table 2). This finding contrasts with the results from other work that suggests norms are central to landscaping decisions (Larson and Brumand 2014; Martini et al. 2015; Nassauer et al. 2009; Nielson and Smith 2005). Thus, more work is needed to unpack norms and how they affect land management priorities across different contexts. Such research should consider internalized versus externalized norms, since a former study 
indicated that landscape norms tend to be internally imposed by residents rather than being externally enforced through interactions among neighbors (Larson and Brumand 2014). Norms may also be shifting, as suggested earlier, away from the expectation that everyone has a lawn - that is, as the most common landscape type in residential areas. Instead, the present study and other recent research suggests that residents may not require or even prefer lawns; yet other norms — such as neatness - are still pervasive (Larson and Brumand 2014).

The dimensions of ecosystem service priorities reflect known value distinctions (Larson 2010; Schultz and Zelezny 1999; Stern and Dietz 1994), as evident in empirical distinctions between provisioning services that are biocentric (i.e., floral biodiversity, native plants and wildlife) versus those that are more anthropocentric (e.g., aesthetics, recreation). Future research should continue to examine ecosystem service priorities and differences based on subjective human values and regional variation in social and environmental characteristics. Such work will aid in developing theory by identifying the extent to which ecosystem service preferences and landscape practices are generalizable across diverse ecosystems, thereby testing the urban homogenization thesis and advancing understanding of how people impact the environmental and society at aggregate levels of regions and nations.

Further research could also reveal the social and environmental contexts in which ecosystem services are seen as more or less valuable. Applied research can inform planners and others by identifying local priorities and tailoring strategies to place-based priorities, considering both human values (e.g., in prioritizing aesthetics or low-maintenance landscape designs) and environmental conditions (e.g., in warm cities such as Miami and Phoenix, design landscapes for cooling benefits).

\section{Landscape priorities and social marketing}

Rather than trying to change people's values - for example, by trying to get them to care more about ecosystem services with ecological benefits, the most effective routes to sustainable behavior change involve working with existing values (Heberlein 2012) and conceptualizations of nature (Dahmus and Nelson 2014a). For this reason, social marketing campaigns are recommended to foster the "cultural sustainability" of landscapes, which has been defined by Joan Nassauer as "ecologically beneficial practices that elicit sustained human attention over time" (p. 1440).

The value placed on low-maintenance yards reflects an overarching priority for enjoyable landscapes that require little effort or time to manage, likely due to people's lack of desire, money, or time to maintain yards (Larson et al. 2009). Associated with this priority, we found that residents value the suitability of local land (yard) conditions, which ultimately determines the quantity of chemicals, time, and other inputs that are required for yard management. As a whole, promoting sustainable yards in urban ecosystems will likely necessitate landscape designs that are attractive to leisurely interests and social constraints such as limited time and other personal priorities (Martini et al. 2015). This requires attention to low-maintenance vegetation choices and yard management practices that address recreational services suited to differentiated social preferences and lifestyles (Larson et al. 2009).

As a whole, when urban planning or land management objectives entail enhancing biodiversity or other environmental values, the most valued cultural services must be considered along with varied tastes and priorities. Enhancing ecologically important services that are of low priority to residents is unlikely to succeed unless the most highly valued services are coupled with others that are not valued as much by locals. This means that enhancing native 
biodiversity or reducing pollution and the effects of climate change, which were of relatively low importance to residents surveyed in this study, should be coupled with landscape designs that offer aesthetically appealing, low-maintenance values for personal enjoyment and social desirability. It is important to note, however, that preferences and priorities for residential landscapes identified in this study may not transfer elsewhere. Previous research supports this warning by demonstrating, for example, that urban residents tend to value cultural services more so than rural residents, who more highly value environmental (e.g., regulating, provisioning) services (Martín-López et al. 2012).

\section{Conclusion}

In sum, ecosystem service priorities across the U.S. regions we surveyed exhibited substantial similarities, or homogeneity, including common preferences for the standard lawn aesthetic (e.g., neat, weed-free, and green landscapes). However, some heterogeneity in landscaping priorities was also found. Specifically, climatic conditions affected the importance of cooling vegetation, such that residents in the warm South value this service more than those in the cool North. Some cultural services also varied by regions, with relative emphasis on beauty in the South and low-maintenance in the North. Altogether, these findings partially support the urban homogenization thesis regarding the values residents attach to ecosystem services; yet they also suggest the need to distinguish among the local values and priorities across diverse metropolitan regions.

The values placed on ecosystem services were distinguishable by dimensions that reflect the different types of provisioning and cultural services established by the Millennium Ecosystem Assessment, as well as biocentric and anthropocentric values. This study also found that the most valued ecosystem services associated with residential landscapes were cultural ones including aesthetics and leisureliness (e.g., personal enjoyment and lowmaintenance designs). These findings underscore the importance of designing landscapes in ways that meet society's anthropocentric priorities, even when promoting or planning for biocentric ecosystem services such as biodiversity or water regulation.

To conclude: just because an ecosystem service exists does not necessarily mean it is valued by people. As such, the subjective values people place on cultural and environmental benefits of certain ecosystems inform their (e.g., residential landscapes) social desirability and sustainability over the long run. Because such research has been rare to-date, this study provides a novel approach to examining the value-based dimensions of ecosystem services. Additional social science research could benefit from adapting the ecosystem services framework and the survey measures developed for this study. In particular, developing a comprehensive and reliable set of ecosystem service benefits and associated survey measures - that are grounded in value theory and other social science perspectives - complements research that has so far been grounded in the fields of ecology and economics. Further, comparable data in different geographic contexts will provide the research needed to empirically test the urban homogenization thesis while also identifying local needs and priorities for urban planners and landscape designers.

Acknowledgments This work was supported by the MacroSystems Biology Program in the Emerging Frontiers Division of the Biological Sciences Directorate at the National Science Foundation (NSF) under grants EF$1065548,1065737,1065740,1065741,1065772,1065785,1065831,121238320$. The work arose from research funded by grants from the NSF Long-Term Ecological Research Program supporting work in Baltimore (DEB0423476), Phoenix (BCS-1026865), Plum Island (Boston) (OCE-1058747), Cedar Creek (Minneapolis-St Paul) 
(DEB-0620652), and Florida Coastal Everglades (Miami) (DBI-0620409). This research was also supported by the NSF-funded Decision Center for a Desert City II: Urban Climate Adaptation (SES-0951366). Any opinions, findings, and conclusions or recommendations expressed in this material are those of the authors and do not necessarily reflect the views of NSF.

\section{References}

Bormann FH, Balmori D, Geballe GT (2001) Redesigning the American lawn: a search for environmental harmony. Yale University Press, New Haven, CT

Cadenasso ML, Pickett ST, Schwarz K (2007) Spatial heterogeneity in urban ecosystems: reconceptualizing land cover and a framework for classification. Front Ecol Environ 5:80-88

Carpenter SR et al (2009) Science for managing ecosystem services: beyond the millennium ecosystem assessment. Proc Natl Acad Sci 106:1305-1312

Chan K, Satterfield T, Goldstein J (2012) Rethinking ecosystem services to better address and navigate cultural values. Ecol Econ 74:8-18

Chazdon RL (2008) Beyond deforestation: restoring forests and ecosystem services on degraded lands. Science 320:1458-1460

Cook EM, Hall SJ, Larson KL (2012) Residential landscapes as social-ecological systems: a synthesis of multiscalar interactions between people and their home environment. Urban Ecosyst 15:19-52

Costanza R, Wilson MA, Troy A, Voinov A, Liu S, D’Agostino J (2006) The value of New Jersey's ecosystem services and natural capital. New Jersey Department of Environmental Protection

Dahmus ME, Nelson KC (2014a) Nature discourses in the residential yard in Minnesota. Landsc Urban Plan 125:183-187

Dahmus ME, Nelson KC (2014b) Yard stories: examining residents' conceptions of their yards as part of the urban ecosystem in Minnesota. Urban Ecosyst 17:173-194

Davenport MA, Anderson DH (2005) Getting from sense of place to place-based management: an interpretive investigation of place meanings and perceptions of landscape change. Soc Nat Resour 18:625-641

De Groot R, Stuip M, Finlayson M, Davidson N (2006) Valuing wetlands: guidance for valuing the benefits derived from wetland ecosystem services. Ramsar Technical Report No. 3, Convention on Biological Diversity Technical Series No. 27, Gland, Switzerland. http://www.ramsar.org/sites/default/files/ documents/pdf/lib/lib rtr03.pdf

De Groot RS, Alkemade R, Braat L, Hein L, Willemen L (2010) Challenges in integrating the concept of ecosystem services and values in landscape planning, management and decision making. Ecol Complex 7:260-272

Farber SC, Costanza R, Wilson MA (2002) Economic and ecological concepts for valuing ecosystem services. Ecol Econ 41:375-392

Frisk E, Larson KL (2011) Educating for sustainability: competencies \& practices for transformative action. J Sustain Educ 2:1-20

Grimm NB, Grove JM, Pickett STA, Redman CL (2000) Integrated approaches to long-term studies of urban ecological systems. Bioscience 50:571-584

Groffman PM et al (2014) Ecological homogenization of urban USA. Front Ecol Environ 12:74-81

Grove JM, Locke DH, O’Neil-Dunne JP (2014) An ecology of prestige in New York city: examining the relationships among population density, socio-economic status, group identity, and residential canopy cover. Environ Manag 54:402-419

Heberlein TA (2012) Navigating environmental attitudes. Oxford University Press, Oxford, UK

Jackson KT (1985) Crabgrass frontier: the suburbanization of the United States. Oxford University Press, New York, NY

Kellner D (2002) Theorizing globalization. Sociol Theory 20:285-305

Kim JO, Mueller CW (1978) Introduction to factor analysis: what it is and how to do it. SAGE Publications Inc., Thousands Oak, California

Kumar M, Kumar P (2008) Valuation of the ecosystem services: a psycho-cultural perspective. Ecol Econ 64:808-819

Larsen L, Harlan SL (2006) Desert dreamscapes: residential landscape preference and behavior. Landsc Urban Plan 78:85-100

Larson KL (2010) An integrated theoretical approach to understanding the sociocultural basis of multidimensional environmental attitudes. Soc Nat Resour 23:898-907

Larson KL, Brumand J (2014) Paradoxes in landscape management and water conservation: examining neighborhood norms and institutional forces. Cities Environ (CATE) 7:6 
Larson KL, Casagrande D, Harlan SL, Yabiku ST (2009) Residents' yard choices and rationales in a desert city: social priorities, ecological impacts, and decision tradeoffs. Environ Manag 44:921-937

Mahan B, Polasky S, Adams R (2000) Valuing urban wetlands: a property price approach land economics. Land Econ 76:100-113

Martin CA, Peterson KA, Stabler LB (2003) Residential landscaping in phoenix, Arizona, US: practices and preferences relative to covenants, codes, and restrictions. J Arboric 9:9-17

Martini NF, Nelson KC, Hobbie SE, Baker LA (2015) Why "feed the lawn"? Exploring the influences on residential turf grass fertilization in the Minneapolis-Saint Paul metropolitan area. Environ Behav 47(2): 158-183

Martín-López B et al (2012) Uncovering ecosystem service bundles through social preferences. PLoS ONE 7 , e38970

McKenzie-Mohr D, Smith W (1999) Fostering sustainable behavior: an introduction to community-based social marketing. New Society Publishers, Gabriola Island B.C., Canada

Milesi C, Running SW, Elvidge CD, Dietz JB, Tuttle BT, Nemani RR (2005) Mapping and modeling the biochemical cycling of turf grasses in the United States. Environ Manag 36:426-438

Millennium Assessment Board (2005) Millennium ecosystem assessment. New Island Press, Washington DC

Nassauer JI (1988) The aesthetics of horticulture: neatness as a form of care. HortSci 23(6):973-977

Nassauer JI (1995) Messy ecosystems, orderly frames. Landsc J 14(2):161-170

Nassauer JI, Wang Z, Dayrell E (2009) What will the neighbors think? Cultural norms and ecological design. Landsc Urban Plan 92:282-292

Nelson E et al (2009) Modeling multiple ecosystem services, biodiversity conservation, commodity production, and tradeoffs at landscape scales. Front Ecol Environ 7:4-11

Nielson L, Smith CL (2005) Influences on residential yard care and water quality: Tualatin watershed, Oregon. J Am Water Resour Assoc 41:93-106

Pataki DE et al (2011) Coupling biogeochemical cycles in urban environments: ecosystem services, green solutions, and misconceptions. Front Ecol Environ 9:27-36

Polsky C et al (2014) Assessing the homogenization of urban land management with an application to US residential lawn care. Proc Natl Acad Sci 111:4432-4437

Robbins P (2007) Lawn people: how grasses, weeds and chemicals make us who we are. Tempe University Press, Philadelphia, PA

Robbins P, Sharp JT (2003) Producing and consuming chemicals: the moral economy of the American lawn. Econ Geogr 79:425 (414)

Robins K, Webster F (1999) Times of the technoculture. Routledge, London

Schultz PW, Zelezny L (1999) Values as predictors of environmental attitudes: evidence for consistency across 14 countries. J Environ Psychol 19:255-265

Schultz PW, Nolan JM, Cialdini RB, Goldstein NJ, Griskevicius V (2007) The constructive, destructive, and reconstructive power of social norms. Psychol Sci 18(5):429-434

Smith WR (1956) Product differentation and market segmentaton as alternative marketing strateiges. J Mark 21(1):3-8

Steele $M$ et al (2014) Convergent surface water distributions in US cities. Ecosystems 17:685-697

Steinberg T (2006) American green: the obsessive quest for the perfect lawn. W.W. Norton and Company, Inc., New York, NY

Stern PC, Dietz T (1994) The value basis of environmental concern. J Soc Issues 50:65-84

Troy AR (2008) Geodemographic segmentation. In: Shenkar S, Xiong H (eds) Encyclopedia of geographical information science. New York, NY: Springer-Verlag, pp 347-355

Vihervaara P, Rönkä M, Walls M (2010) Trends in ecosystem service research: early steps and current drivers. Ambio 39:314-324

Wallace KJ (2007) Classification of ecosystem services: problems and solutions. Biol Conserv 139:235-246

Wedel M, Kamakura W (2000) Market segmentation: conceptual and methodological foundations. International series in quantitative marketing, 2nd edn. Kluwer Academic Publishers, Newell, Massachusetts

Williams DR, Stewart SI (1998) Sense of place: an elusive concept that is finding a home in ecosystem management. J For 96:18-23 